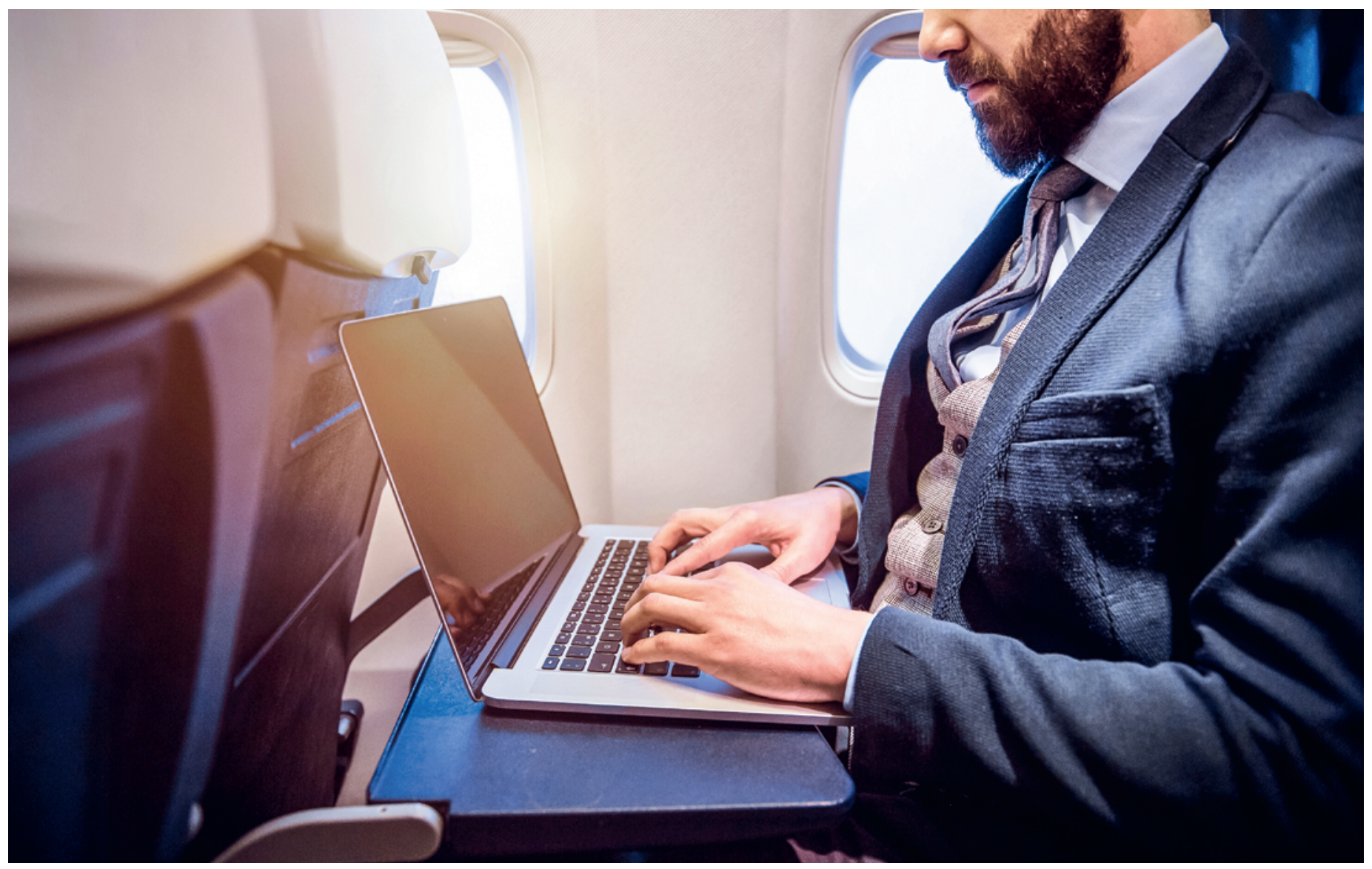

\title{
Willkommen an Bord
}

\section{Zeno Schneider}

Dr. med, Mitglied der FMH

Das Flugzeug hat Fensterplätze. Sie bieten eine wunderbare Sicht auf die Weite des Himmels, die Flächen der Erde und die Breite der Meere.

Mrs. Quaddelbee hat einen Fensterplatz. Sie schaltet sofort einen Film ein und verdunkelt die Scheibe. Jetzt muss sie nicht mehr fliegen, sondern nur noch Filmschauen, was sie schon aufgrund ihres Körperbaus auch viel besser kann.

Mr. Mortimer hat auch einen Fensterplatz. Er schaltet sofort seinen Laptop ein und starrt von Paris bis tief in den Atlantik auf das flimmernde Desktop. Jetzt muss er nicht nur fliegen, sondern er kann ungestört arbeiten, was seiner Karriereplanung sehr entgegenkommt.

$M^{\text {Ile }}$ Héloïse de Grée hat ebenfalls einen Fensterplatz. Sie blättert sofort in einer Modezeitschrift. So muss sie nicht bloss fliegen, wenn sie die Kollektionsfarben der nächsten Saison verinnerlicht.

Als die Maschine in einige Turbulenzen gerät, werden Mrs. Quaddelbee, Mr. Mortimer und Mademoiselle de Grée leicht ungehalten. Turbulenzen im Kino, bei der Karriereplanung und beim Studium der Modefarben sollten wirklich nicht vorkommen. 